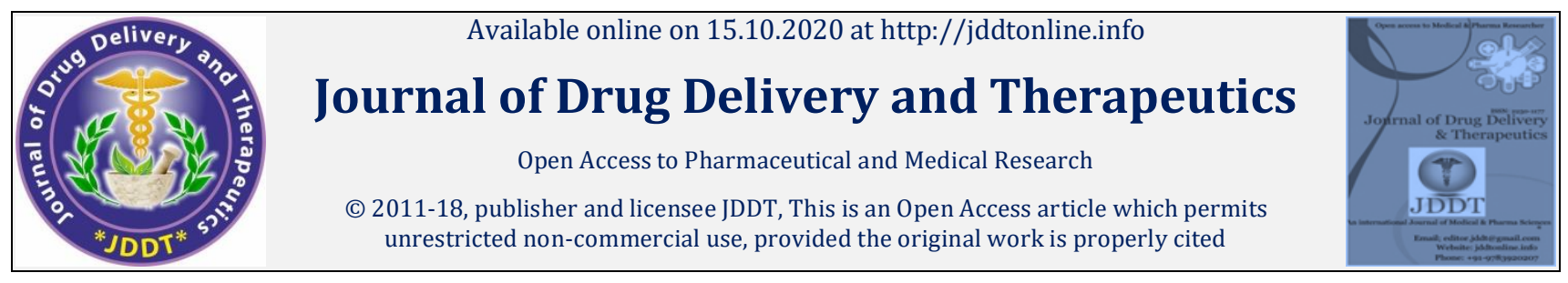

Open $\odot$ Access

Research Article

\title{
In-vivo Evaluation and Characterization of Novel In-Situ Gelling System as Controlled Delivery System Containing Ciprofloxacin for Ocular Drug Delivery
}

\author{
Fatima Eram *, Vivek \\ Department of Pharmacy, IIMT College of Pharmacy, Greater Noida, G.B Nagar, U.P., India
}

\begin{abstract}
Objectives: The purpose of this research was to develop the micro emulsion-based in situ gelling systems containing Ciprofloxacin for prophylaxis and treatment of the posterior segment diseases like endophthalmitis.

Methods: Ciprofloxacin was encapsulated in small droplets owing to form microemulsion, and then the formed droplets were dispersed in a polymer solution that converted into a gel upon triggered by the electrolyte present in the tear fluid.

Results: The formulation approach provides better absorption, penetration, retention, and improves the bioavailability of the drug. The average concentration reached into vitreous humor from topical microemulsion in situ gelling formulation was $\sim 0.4 \mu \mathrm{g} / \mathrm{ml}$, which is far more than the concentration required for therapeutic effect (i.e. $>0.047 \mu \mathrm{g} / \mathrm{ml}$ or $>$ MIC90 for S. Epidermidis, a pathogen commonly responsible to cause endophthalmitis).
\end{abstract}

Conclusion: Thus, novel micro emulsion-based in situ gelling formulation could be a potential drug delivery system for the treatment of posterior segment diseases like endophthalmitis.

Keywords: Microemulsion, ciprofloxacin, endophthalmitis, ocular, infection, in situ

Article Info: Received 07 Aug 2020; $\quad$ Review Completed 13 Sep 2020; $\quad$ Accepted 19 Sep 2020; $\quad$ Available online 15 Oct 2020

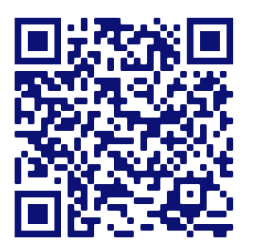

Cite this article as:

Eram F, Vivek, In-vivo Evaluation and Characterization of Novel In-Situ Gelling System as Controlled Delivery System Containing Ciprofloxacin for Ocular Drug Delivery, Journal of Drug Delivery and Therapeutics. 2020; 10(5-s):32-39 http://dx.doi.org/10.22270/jddt.v10i5-s.4421

Ms. Eram Fatima, Research scholar, IIMT College of Pharmacy, Knowledge Park III, Greater Noida, G.B Nagar Greater Noida, G.B Nagar, Uttar Pradesh 201308

\section{INTRODUCTION}

Endophthalmitis is an infection of intraocular fluids like vitreous humor and ocular tissues. To combat the disease, the formulation which provides sufficient concentration in the posterior segment is required 1 . Ciprofloxacin is well reported for the treatment of endophthalmitis, it has better penetration into ocular tissues and high potency compared to many of the same class drugs ${ }^{2}$.

\section{Drugs used in Endophthalmitis}

For an ocular antibiotic selection, one should evaluate four main characteristics of antibiotics. First, the drug must be able to effectively penetrate into the intraocular tissues. Second, the drug must be of adequate potency, which, in the case of antibiotics, is measured by the mean inhibitory concentration (MIC). Third, there must be minimal bacterial resistance to the drug3. Finally, the drug should be able to rapidly eradicate bacteria, before the infection is able to set in. Generally, the broadspectrum antibiotic is required for severe visionthreatening infections such as Endophthalmitis. The fourth-generation fluoroquinolones such as Ciprofloxacin and Gatifloxacin can provide better coverage for grampositive and resistant organisms than the thirdgeneration fluoroquinolone such as levofloxacin, and the second-generation fluoroquinolones such as Ciprofloxacin and Ofloxacin ${ }^{4}$.

\section{Therapeutic challenges}

The factors to be considered during the treatment of endophthalmitis are the delicate nature of the interior of the eye and the anatomic barriers. The key anatomic barriers that prevent adequate treatment of endophthalmitis are the inner and outer blood-retinal barrier and the blood-aqueous humor barrier collectively called the blood-ocular barrier ${ }^{5}$. The blood-ocular barrier 
consists of tight junctions between the endothelial cells and the basement membrane of retinal capillaries and retinal pericytes. The role of the barrier is to protect the interior of the eye from assault by cells, macromolecules, and drugs \& prevent the entrance and subsequent activity of most systemic antimicrobial and anti-inflammatory drugs $^{6}$. Direct injection of drugs into the vitreous humor can bypass the intraocular barriers. Photoreceptors and other cells of the retina are extremely sensitive to insult, and high doses of antimicrobial agents required to eradicate the bacteria from the eye may induce toxic effects on the retina and it may potentially disrupting the biochemical pathways necessary for vision. For the treatment of some vitreoretinal diseases, systemic administration of drugs has been used 7 . But the literature said that after systemic administration, a very small amount of drugs could reach the eye. Therefore to obtain a therapeutic level of drug concentration in the eye, a large amount of systemic dose is required 8 .

\section{The rationale of the system in the topical treatment of} Endophthalmitis

Endophthalmitis is the infection of the posterior chamber of Eye. The topical application of contemporary available marketed formulations has various drawbacks in the treatment of endophthalmitis due to rapid and extensive precorneal loss ${ }^{9}$. Typically, less than $5 \%$ of the drug applied penetrates the cornea/sclera and reaches the intraocular tissue, with the major fraction of the dose applied often absorbed systemically through the conjunctiva and nasolacrimal duct 10 . This can result in undesirable systemic side effects. Other routes like periocular (oral and systemic) medications require a high dose to achieve and maintain MIC90 in vitreous humor hence causing higher toxicity, and Intra-vitreal injection remains remain major treatment option for treatment of endophthalmitis. It also has drawbacks like patient noncompliance, very expensive, requires hospitalization, invasive technique, frequent puncturing, etc. In addition, due to the accumulation of drugs at posterior tissues, it causes retinal tissue damage ${ }^{11}$.

\section{MATERIAL AND METHODS}

\section{Chemicals and reagents}

Ciprofloxacin Hydrochloride, Labrasol (Polyethylene glycol-8-glycol caprylate, Transcutol (Diethylene glycol monoethyl ether, Labrafil M 2125 (PEG -6 corn oil), Food Grade, Isopropyl Myristate, Castor oil, Oleic acid, Tween 20, Tween 80, Span 80, Propylene glycol, PEG 400, Benzalkonium chloride, Mannitol, Carbopol 934, Sodium alginate, Sodium bicarbonate, Sodium chloride, Sodium hydroxide, Methanol AR, Calcium chloride dehydrate, HPLC-grade acetonitrile, Orthophosphoric acid, Potassium dihydrogen ortho, phosphateHPLC grade Methanol, Membrane filter $0.45 \mu \mathrm{m}$, Membrane filter 0.22 $\mu \mathrm{m}$ gifted \& procured by Gattefosse, Merck India Ltd, India, Central drug house Pvt. Ltd, India \& S.D. Fine-chem Ltd, India. All other unlabelled chemicals and reagents were analytical grade.

\section{List of Equipment}

Digital balance, Electronic Weighing Balance, Mechanical Stirrer, Vortex shake, Hot air oven, Ultraviolet spectrophotometer, Refrigerated microcentrifuge, Humidity control oven, Ultrasonicator, pH meter, Malvern-Zetasizer, Brookfield viscometer, Q T S Texture Analyser, Fourier Transformed.

\section{Preparation of simulated tear fluid (pH 7.4)}

Sodium chloride ( $\mathrm{NaCl})$

Sodium bicarbonate (NaHCO3)

Dihydrated Calcium chloride ( $\mathrm{CaCl} 2.2 \mathrm{H} 2 \mathrm{O})$

Purified bidistilled water

Characterization of in situ gelling system

\section{pH Measurements}

The $\mathrm{pH}$ was measured for each formulation using a $\mathrm{pH}$ meter, which was calibrated before use with buffered

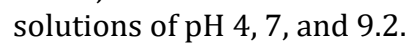

\section{Rheological Studies}

The viscosity of the prepared formulations was determined by Brookfield viscometer at different angular velocities at $34 \pm 1$ 0C. A typical run for viscosity measurement involved changing the angular velocity from 0.5 to $100 \mathrm{rpm}$ at a controlled ramp speed. After 6 seconds at $0.5 \mathrm{rpm}$, the velocity was successively increased to 100 rpm, with a similar time period at each speed ${ }^{12}$. The angular velocity was then decreased likewise (100-0.5 $\mathrm{rpm}$ ) for a similar period of 6s. (60) The mean of two readings was used to calculate the viscosity of the formulation. The formulation was evaluated for change in viscosity after administration, rheological measurements were taken after diluting the prepared formulations with artificial tear fluid $(0.67 \% \mathrm{NaCl}, 0.2 \% \mathrm{NaHCO}, 0.008 \%$ $\mathrm{CaCl} 22 \mathrm{H} 2 \mathrm{O}$ ) in 25:7 ratio (application volume, $25 \mu \mathrm{l}$; a normal volume of tear fluid in the eye, $7 \mu \mathrm{l}$ ).

\section{Gelling Capacity}

The gelling capacity was determined by placing a drop of the formulation in a Petri dish containing $2 \mathrm{ml}$ of simulated tear fluid (STF) freshly prepared and equilibrated at $37^{\circ} \mathrm{C}$ and visually assessing the gel formation and noting the time for gelation and the time taken for the gel formed to dissolve ${ }^{13}$.

\section{Gel Strength Determination}

The gel strength of the formulation was determined using a Brookfield Texture Analyzer (USA) in compression mode. Formulations with STF $(50+14 \mathrm{ml})$ were transferred into a cylindrical holder; care was taken to avoid the introduction of air into the samples. A cylindrical analytical probe (diameter $38 \mathrm{~mm}$ ) was forced down into each sample at a defined rate of $30 \mathrm{~mm} / \mathrm{min}$ and to a defined depth of $10 \mathrm{~mm}$. Three replicate samples were analyzed with the simulated tear fluid. From the resulting load-time plots, the gel strength (the maximum force required to attain a given deformation) and adhesive force (the work necessary to overcome the attractive forces between the surface of the sample and the surface of the probe) were determined 14 .

\section{In-vivo Evaluation}

\section{Eye Irritation Test in Rabbit}

Rabbits weighing 1.5-2.5 kg were treated with one drop in the right eye twice a day with the optimized formulation for 3 days. The left eye of each animal served as control and was treated with normal saline. The condition of eyes was recorded after $1 \mathrm{hr}$ of each administration and at a specific time every day. According to the Draize test, ocular irritation scores were calculated by adding 
together the irritation scores for the cornea, iris, and conjunctiva for each animal ${ }^{15}$.

The eye irritation score was calculated by dividing the total score for all animals by the number of animals. Irritation was classified into four grades: practically nonirritating (score 0-3); slightly irritating (score 4-8); moderately irritating (score 9-12); and severely irritating or corrosive (score 13-16) ${ }^{16}$.

\section{Determination of Vitreous Penetration of Drug}

Rabbits were marked as 1 to 4 . Rabbits were treated three times a day (instillation of one drop in the right eye) with optimized formulation for 3 days. The left eyes served as controls and were treated with marketed eye drops ${ }^{17}$.

\section{Vitreous humor collection procedure}

It is the same as the application of intravitreal injection. But the difference is, instead of an application, blank injection is injected and vitreous humor is collected up to the mark in the syringe (previously calibrated $50 \mu \mathrm{l}$ and $100 \mu \mathrm{l}$ with the help of micropipettes) ${ }^{18}$.

Each rabbit was anesthetized by i.m. injection of a mixture of Xylazine $\mathrm{HCl}$ (10 mg/kg) and Ketamine $\mathrm{HCl}(50 \mathrm{mg} / \mathrm{kg}$ ). When the rabbit was anesthetized, $2 \%$ lidocaine was applied in the eye at the injection site to provide local anesthesia. Then eyelash and eyeliners/lids were wiped with $5 \%$ povidone solution maintaining standard of care to give an intravitreal injection. $5 \%$ povidone was also added at the injection site to prevent any infection to induce. Than $4 \mathrm{~mm}$ distance from the limbus was measured with the help of calipers and intravitreal injection was given with 31 gauze insulin syringe and vitreous humor was collected. The depth of the insertion is $5 \mathrm{~mm}^{19}$.

\section{Vitreous humor treatment}

To $0.1 \mathrm{ml}$ of the vitreous humor sample, $0.1 \mathrm{ml}$ of acetonitrile was added and mixed to precipitate out proteins. The mixture was centrifuged at 10000 RPM for $15 \mathrm{~min}$ and the supernatant was collected ${ }^{20}$.

\section{Analysis of the sample}

Samples (supernatant) were analyzed by HPLC for the estimation of drug concentration in the vitreous humor.

\section{Stability Study}

Stability is defined as the extent to which a product retains, within specified limits, and throughout its period of storage and use (i.e. its shelf life), the same properties and characteristics that it possessed at the time of its manufacture. Stability testing is performing to ensure that drug products retain their fitness for use until the end of their expiration dates. A stability study was carried out for sterilized, final formulations at $25^{\circ} \mathrm{C} \pm 2{ }^{\circ} \mathrm{C} / 60 \% \pm 5 \%$ RH conditions for 6 months. Samples were analyzed at 3 and 6 months for visual appearance, particle size, zeta potential, viscosity, $\mathrm{pH}, \%$ transmittance, and drug content ${ }^{1}$.

\section{Statistical analysis}

The results are expressed as mean \pm S.E.M. Statistical analysis of passive avoidance, Morris water maze, and biochemical values were performed by comparison Duncan's multiple range test (DMRT).

\section{RESULTS AND DISCUSSION}

\section{Characterization of Microemulsion}

The physicochemical characteristics of the developed ME are summarized in Table 1 . The developed ME has very little viscosity, which renders it pourable for installation in the eye. It shows \% transmittance value > $98 \%$ which proves the transparency of the system and globules are in nanometer dimensions, confirmed by the value obtained for globule size (22.95-51.6 nm). The prepared microemulsion was physically stable at room temperature for a long period of time without the occurrence of phase separation and significant change in globule size. The solubility data of Ciprofloxacin in microemulsion showed that the required amount of drug can be dissolved in microemulsion to obtain microemulsion formulation ${ }^{21}$.

Table 1: Characterization of Microemulsion

\begin{tabular}{|c|c|c|c|c|c|c|}
\hline Run & $\begin{array}{c}\text { Globule size } \\
\mathbf{( n m )}\end{array}$ & PDI & $\begin{array}{c}\text { Zeta Potential } \\
\mathbf{( m V )}\end{array}$ & Transmittance (\%)* & $\begin{array}{c}\text { Solubility of drug } \\
\mathbf{( m g / m l )}\end{array}$ & $\begin{array}{c}\text { Drug content } \\
\text { (\%)* }\end{array}$ \\
\hline $\mathbf{1}$ & 32.30 & 0.100 & -0.390 & $99.82 \pm 0.001$ & 16.02 & $98.91 \pm 0.51$ \\
\hline $\mathbf{2}$ & 51.60 & 0.096 & -0.293 & $98.56 \pm 0.002$ & 11.78 & $99.63 \pm 0.20$ \\
\hline $\mathbf{3}$ & 22.95 & 0.692 & -0.158 & $99.84 \pm 0.004$ & 9.87 & $98.06 \pm 0.55$ \\
\hline $\mathbf{4}$ & 46.50 & 0.118 & -0.592 & $99.32 \pm 0.001$ & 14.83 & $100.35 \pm 0.43$ \\
\hline $\mathbf{5}$ & 29.87 & 0.190 & -0.494 & $99.49 \pm 0.002$ & 13.67 & $102.06 \pm 0.25$ \\
\hline $\mathbf{6}$ & 43.90 & 0.060 & -0.274 & $99.11 \pm 0.003$ & 10.62 & $99.36 \pm 0.83$ \\
\hline $\mathbf{7}$ & 41.00 & 0.127 & -0.482 & $98.87 \pm 0.002$ & 11.36 & $97.76 \pm 0.45$ \\
\hline $\mathbf{8}$ & 31.10 & 0.067 & -0.312 & $99.86 \pm 0.002$ & $98.58 \pm 0.41$ \\
\hline
\end{tabular}

The drug permeation was higher from the ME. This may be due to high solubilization capacity, as well as the potential of ME to enhance permeability. 


\section{Rheological behavior}

Table 1 \& Figure 5.25 show the rheology of different formulations. The formulations showed pseudo-plastic rheology, concluded from shear thinning, and a decrease in the viscosity with increased angular velocity ${ }^{22}$.

Table 2: Rheology profiles of different formulations

\begin{tabular}{|c|c|c|c|c|c|c|c|}
\hline \multirow[b]{2}{*}{ RPM } & \multicolumn{7}{|c|}{ Viscosity (Cps) } \\
\hline & F1 & F2 & F3 & F4 & F5 & F6 & F13 \\
\hline 0.5 & 589 & 820 & 1018 & 739 & 1098 & 1898 & 782 \\
\hline 1 & 410 & 669 & 878 & 681 & 1008 & 1584 & 704 \\
\hline 5 & 291 & 498 & 710 & 591 & 872 & 1189 & 601 \\
\hline 10 & 211 & 428 & 609 & 529 & 711 & 938 & 540 \\
\hline 20 & 193 & 390 & 581 & 490 & 621 & 816 & 515 \\
\hline 50 & 169 & 351 & 551 & 435 & 573 & 800 & 461 \\
\hline 60 & 171 & 328 & 532 & 408 & 554 & 772 & 442 \\
\hline 100 & 158 & 317 & 517 & 376 & 540 & 765 & 401 \\
\hline
\end{tabular}

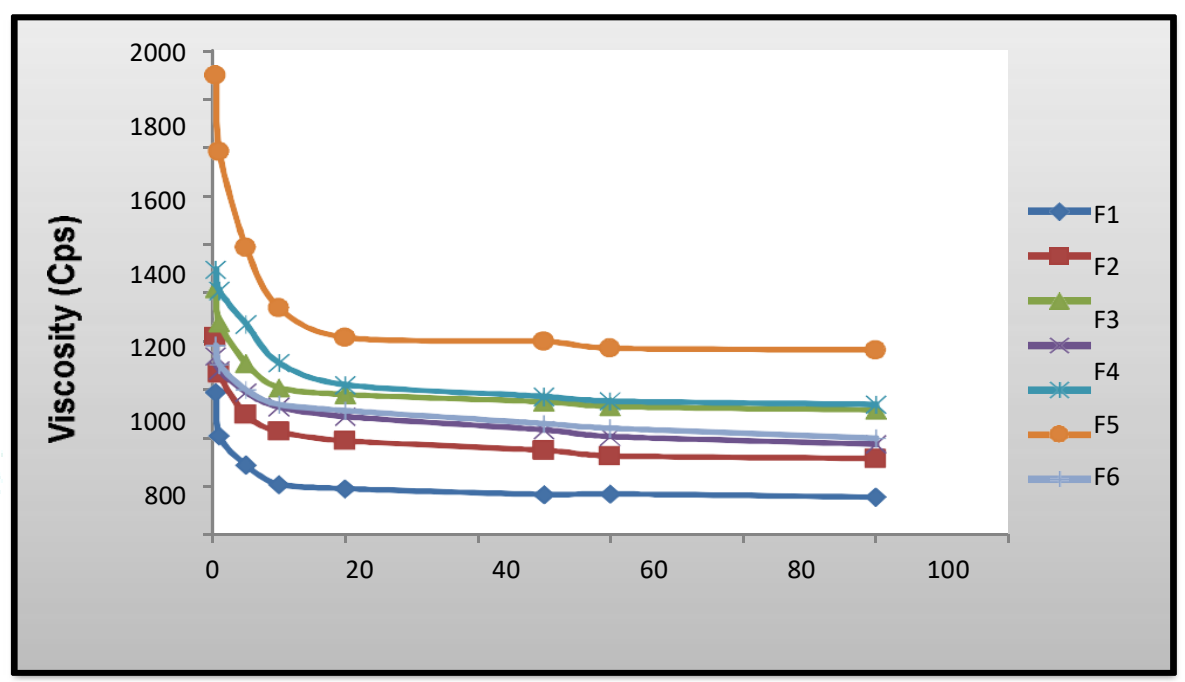

Figure 1: Rheology profiles of different in situ gelling formulations

The results demonstrate that dilution with artificial tear fluid dramatically increased the viscosity of in situ gelling formulations containing Kelcogel $F$ and/or Sodium alginate. This phenomenon confirms the in situ gelling property of the polymer system. The percentage change in viscosity of formulations by the addition of STF (at 0.5 rpm) is shown in Figure.

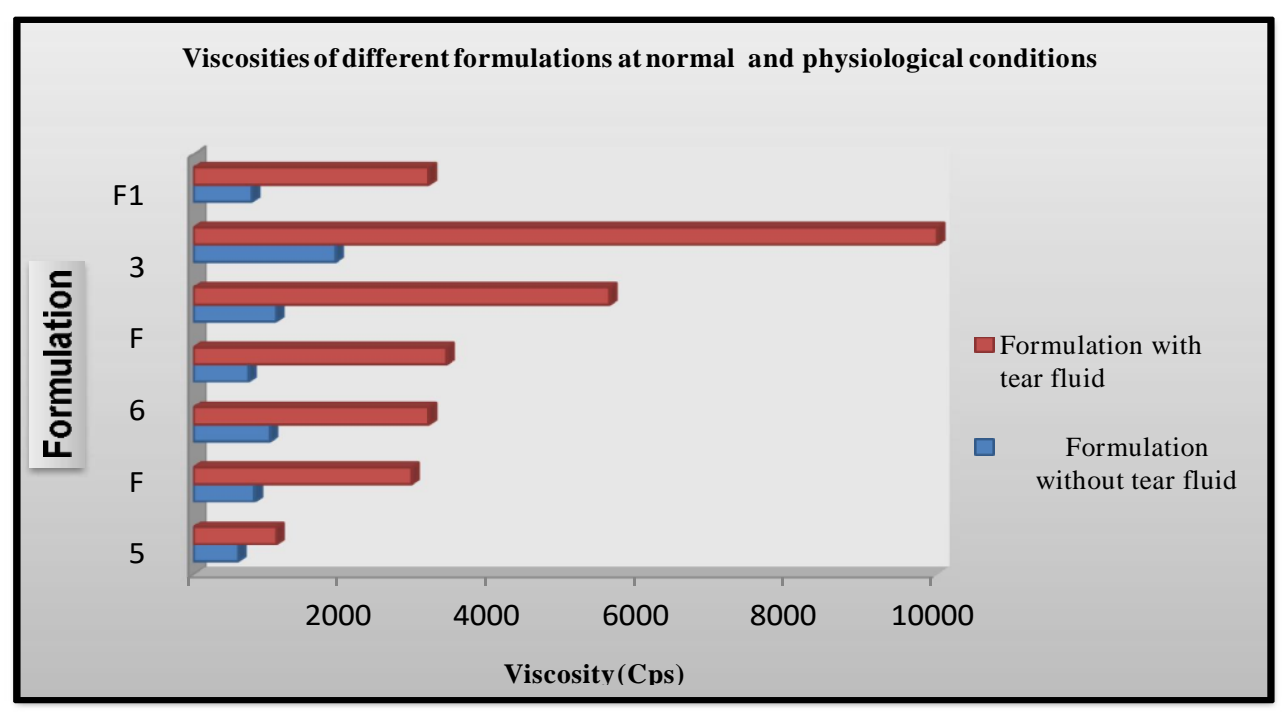

Figure 2: Viscosity of formulations with and without artificial tear fluid 


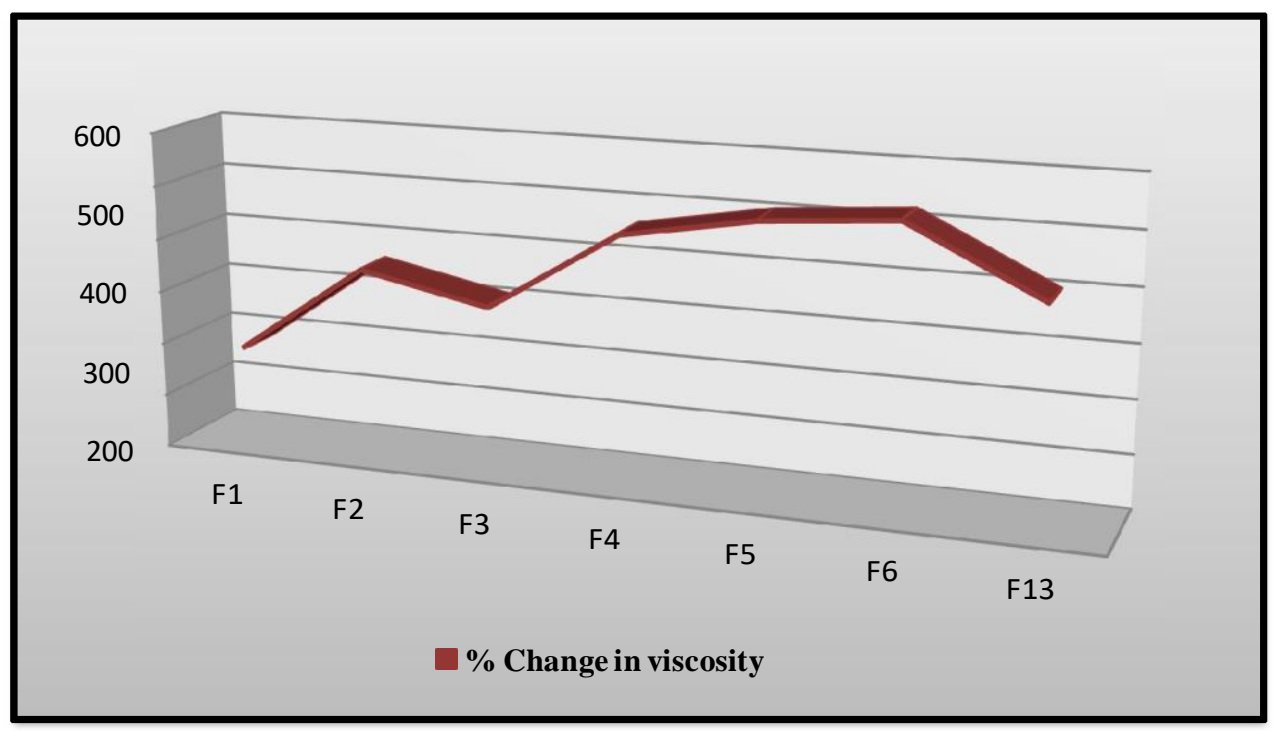

Figure 3: Percentage change in viscosity

\section{In-vivo Evaluations}

\section{Ocular Irritation}

An ocular irritation study was performed using healthy albino rabbits after getting prior permission from the institutional animal ethics committee. The eyes of each rabbit were examined at a particular time interval after the installation of the optimized formulation. There was no redness, continuous blinking, swelling, or watering of eyes. No ocular damage or abnormal clinical signs to the cornea, iris, or conjunctiva were visible. The result of ocular irritation studies indicates that formulation is nonirritant to the rabbit eye ${ }^{23}$.

Table 3: Observed eye irritation in rabbits

\begin{tabular}{|c|c|c|}
\hline \multirow{2}{*}{$\begin{array}{c}\text { Rabbit } \\
\text { Number }\end{array}$} & \multicolumn{2}{|c|}{ Observed Eye Irritation } \\
\cline { 2 - 3 } & Eye Drops (Std drug) & Formulated ME In-Situ Gel \\
\hline 1 & 0 & 0 \\
\hline 2 & 1 & 1 \\
\hline 3 & 0 & 1 \\
\hline 4 & 0 & 1 \\
\hline
\end{tabular}

Irritation was classified according to four grades: practically non-irritating (score 0-3); slightly irritating (48); moderately irritating (9-12); and severely irritating or corrosive (13-16). The eye irritation score was obtained by dividing the total score for all rabbits by the number of rabbits. From Table 5.45, it was observed that the eye irritation score of marketed eye drops (Moxicon) was 0.25 and that of formulated ME in situ gel was 0.75 . Thus, it was concluded that all formulations exhibited an eye irritation score $<1$ and has excellent ocular tolerance ${ }^{24}$.

\section{Determination of Vitreous Penetration of Drug}

The penetration of drug in vitreous humor was determined 45 minutes after the last installation in multiple-dose regimens (three times a day for three days). The formulated ME in situ gel was administered in the left eye and marketed eye drops (Moxicon) were instilled into the right eye as a control ${ }^{25}$. The drug concentration in the vitreous was determined using the HPLC method and results were shown in Table. 


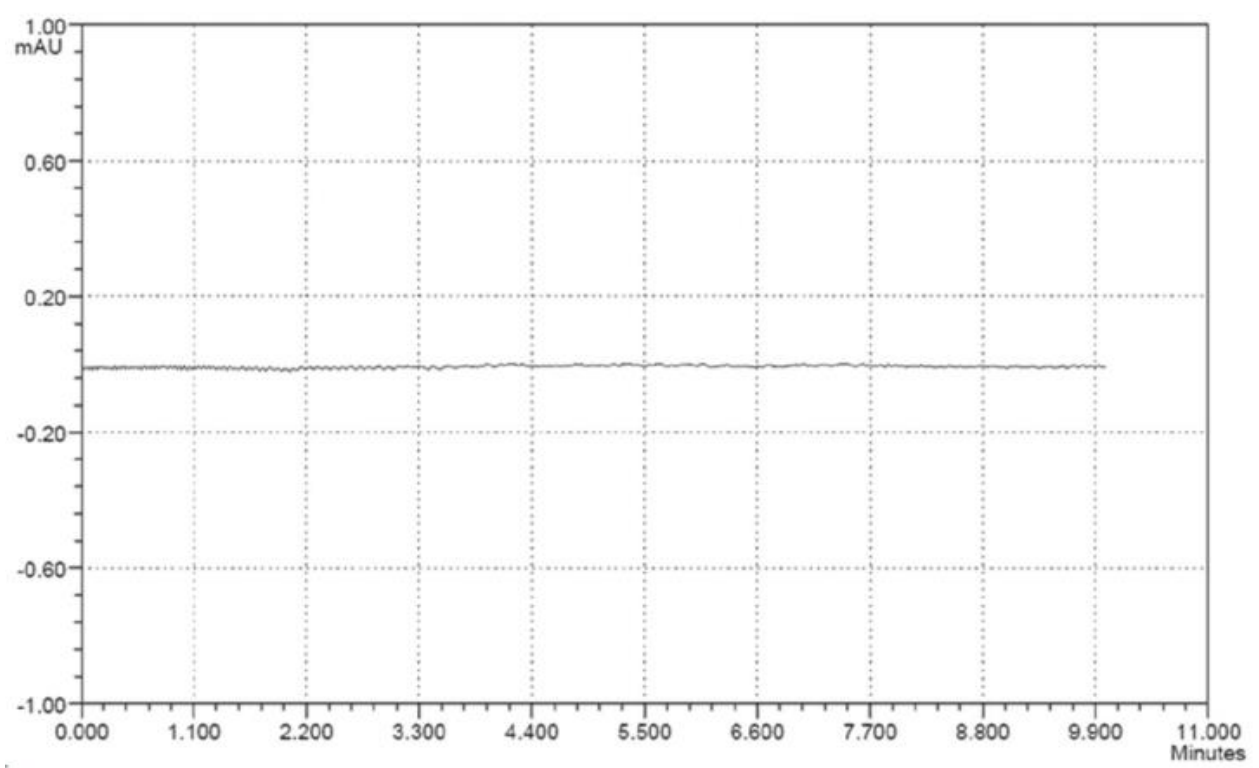

Figure 4: Chromatogram of blank vitreous humor sample

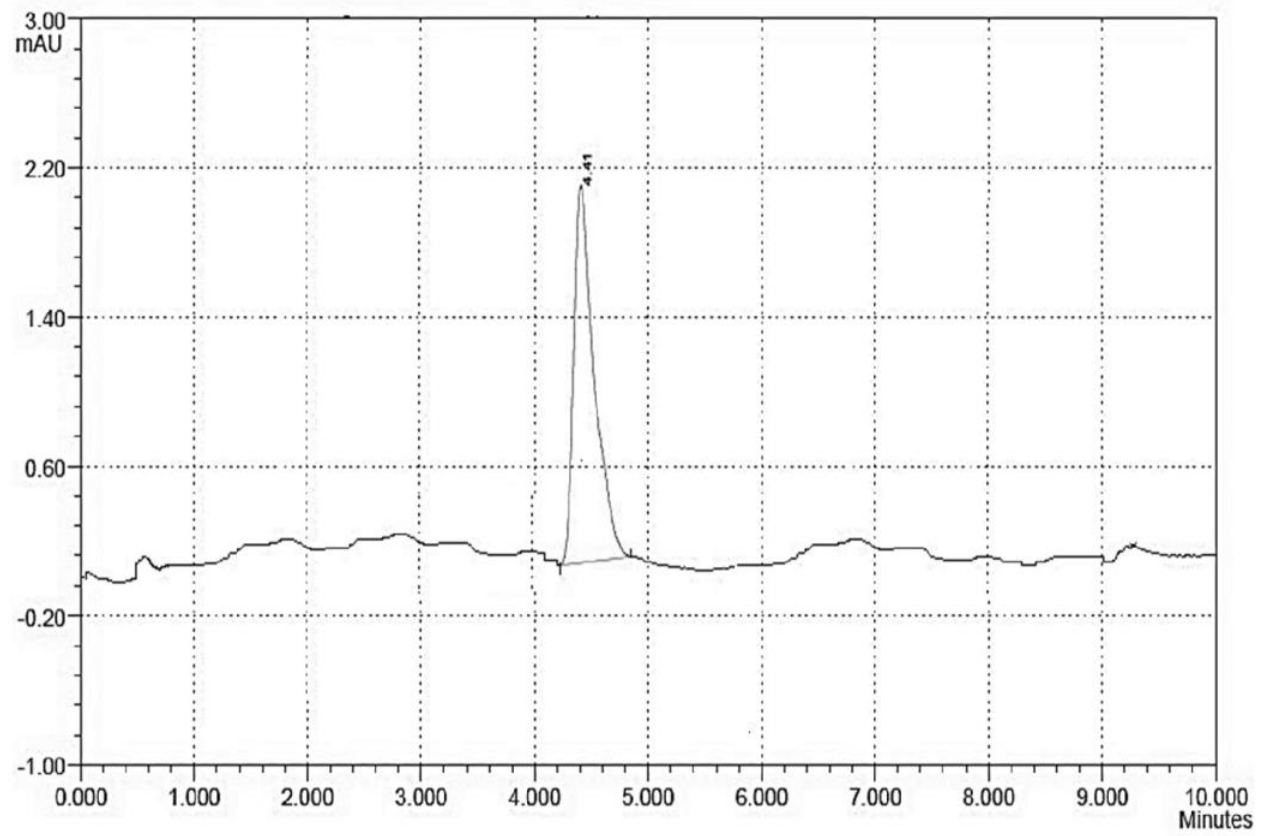

Figure 5: Chromatogram of vitreous humor containing drug

Table 4: Determination of drug concentration in the vitreous humor

\begin{tabular}{|c|c|c|}
\hline Vitreous Sample (Left Eye) & $\begin{array}{c}\text { Peak Area } \\
(\mu \mathrm{V} . \mathrm{Sec})\end{array}$ & $\begin{array}{c}\text { Conc. in Vitreous Humor } \\
(\mu \mathrm{g} / \mathrm{ml})\end{array}$ \\
\hline Rabbit 1 & 10736 & 0.406 \\
\hline Rabbit 2 & 10007 & 0.383 \\
\hline Rabbit 3 & 10926 & 0.412 \\
\hline Rabbit 4 & 12826 & 0.472 \\
\hline Average & 11124 & 0.418 \\
\hline
\end{tabular}


From HPLC analysis, it was found that no drug was detected in vitreous humor collected from the right eyes, and sufficient drug was detected in vitreous humor collected from the left eyes ${ }^{26}$. The average conc. reached into vitreous humor was $\sim 0.4 \mu \mathrm{g} / \mathrm{ml}$, which is far more than conc. required for therapeutic effect (i.e. $>0.1 \mu \mathrm{g} / \mathrm{ml}$ or $>>$ MIC90 for $S$. Epidermidis, a pathogen commonly responsible to cause endophthalmitis). Thus, novel microemulsion based in situ gelling formulation could be a potential drug delivery system for posterior segment diseases like endophthalmitis ${ }^{27}$.

The study indicated that the formulation was physically and chemically stable as there were no significant changes in any of the evaluated parameters observed when stored at the $25^{\circ} \mathrm{C} \pm 2{ }^{\circ} \mathrm{C} / 60 \% \pm 5 \% \mathrm{RH}$ conditions for 6 months ${ }^{28}$. There are many important aspects that control the stability of Microemulsion together like low interfacial tension, droplet charge, presence of steric stabilizing layer, viscosity, etc. Microemulsion differs in several important aspects from the emulsion. They are thermodynamically stable as opposed to the kinetic stability of the emulsion. The stability arises mainly from the very low interfacial tension, achieved through the surfactant/co-surfactant mixture, between the droplets and the bulk phase. Particle size and zeta potential were measured after 6 months of stability period and values obtained were $45.80 \mathrm{~nm}$ and $-0.49 \mathrm{mv}$ respectively which were not significantly changed from the initial values 29 . The particle size was in nanoscale which contributes to the stability of the Microemulsion, owing to the large entropy of dispersion involved 30 . Zeta's potential value was slightly negative which indicated the stability of formulations as there were fewer chances of globule aggregation. Thus it was concluded that the Microemulsion based in- situ gel system for ocular drug delivery was stable during 6 month period 31 .

\section{CONCLUSIONS}

In the study, we had investigated for the potential of a microemulsion based in situ electrolyte-triggered gelling systems for specific delivery of Ciprofloxacin to posterior ocular tissue and fluids. Compared to two other formulations, those are in situ gelling system and eye drop solutions, the Ciprofloxacin microemulsion based in situ gelling system showed better penetration into ocular tissues, higher Ciprofloxacin levels in the vitreous humor, and prolonged residence in the cornea ${ }^{32}$.

After 45 minutes of the last dosing in three times, a day for a 3-days regimen, a sufficient Ciprofloxacin concentration (>>MIC90 for most of the pathogens responsible for Endophthalmitis) was detected in the vitreous humor, which suggests the potential of Ciprofloxacin microemulsion in situ gelling systems for delivery of the drug to the posterior chamber of the eye ${ }^{33}$. In vivo, ocular irritation test on animals revealed good compatibility of the system. Therefore, it is concluded that the Ciprofloxacin microemulsion in situ gelling system might represent an alternative for the treatment of endophthalmitis ${ }^{34}$.

\section{ACKNOWLEDGEMENT}

The authors are thankful to IIMT College of Pharmacy, Knowledge Park III Greater Noida, for providing infrastructure and assistance towards this research work.

\section{CONFLICT OF INTEREST}

The authors declare no conflict of interest. ISSN: 2250-1177

\section{REFERENCES}

1. Sushama T, Adnan A, Farhan JA, Microemulsion: A novel approach to enhanced drug delivery. Recent Patents on Drug Delivery \& Formulation, 2008; 2:238-57.

2. Sumedha N, Chandrakant L et al, Current Trends in Novel Drug Delivery an OTC Perspective. Pharma Times, 2010; 42:17-23.

3. Vandamme TF, Microemulsions as ocular drug delivery systems: recent developments and future challenges. Progress in Retinal and Eye Research, 2002; 21:15-34.

4. Kumar K, Senthil D, Saravanan, Microemulsions as carrier for novel drug delivery: A review, Int J Pharma Sci Rev and Res, 2011;10:37-45.

5. Peltola S, Saarinen P, Kiesvaara J, et al, Microemulsions for topical delivery of estradiol. Int. J. Pharm, 2003; 254:99-107.

6. Huang C, Xueling C, Dandong D, et al, Microemulsion-based hydrogel formulation of ibuprofen for topical delivery. Int J Pharmaceutics, 2006; 351:52-58.

7. Spielen P, Homar M, Zupancic-Valant A, et al. Sodium ascorbyl phosphate in topical microemulsions. Int. J. Pharm. 2003; 256:65-73.

8. Suthar M, Modi JD, Patel MP, et al, Microemulsion-Based gel formulation and evaluation of tretinoin for topical delivery. Int J Pharma res, 2009; 1(4):28-34.

9. Lawrence MJ, Surfactant systems: microemulsion and vesicles as vehicles for drug delivery. Eur J Drug Metab Pharmacokin, 1994; 3:257-269.

10. Sariciaux MJ, Alan L, Sado PA, Using microemulsion for drug delivery of therapeutic peptides. Int J Pharmaceutics, 1995; 12:127-136.

11. Swenson EC, Curatolo W, Intestinal permeability enhancement for proteins, peptides, and other polar drugs: mechanism and potential toxicity. Adv Drug Del Rev, 1992; 8:39-42.

12. Kyung MP, Chong-Kook K, Preparation and evaluation of flurbiprofen- loaded microemulsion for parenteral delivery. Int J Pharma, 1999; 181:173-79.

13. Lee JM, Park KM, Lim SJ, et al, Microemulsion formulation of clonic acid: solubility enhancement and pain reduction. J Pharmacy Pharmacol, 2002; 54:43-49.

14. Rhee YS, Park CW, Nam TY, et al, Formulation of parenteral microemulsion containing itraconazole. Archives of Pharmacal Res, 2007; 30:114-23.

15. Ryoo HK, Park CW, Chi SC, et al, Development of propofol loaded microemulsion systems for parenteral delivery. Archives of Pharmacal Res. 2005; 28:1400-04.

16. Hwang SR, Lim SJ, Park JS, et al, Phospholipids based microemulsion formulation for all-trans-retinoic acid for parenteral administration. Int J Pharmaceutics, 2004; 276:175-83.

17. Zhao X, Chen D, Gao P, et al, Synthesis of Ibuprofen eugenol ester and its microemulsion formulation for parenteral delivery. Chem Pharma Bulletin, 2005; 53:1246-50.

18. Jumma M, Muller BW, The effect of oil components and homogenization conditions on the physicochemical properties and stability of parenteral fat emulsions. Int J Pharmaceutics, 1998; 163:81-89.

19. Kriwet K, Muller-Goymann CC, Diclofenac release from phospholipid drug systems and permeation through excised human stratum corneum. Int J Pharmaceutics, 1995; 125:23142.

20. Trotta M, Morel S, Gasco MR, Effect of oil phase composition on the skin permeation of felodipine from w/o microemulsions. Pharmazie, 1997; 52: 50-53.

21. Chen $\mathrm{H}$, Chang $\mathrm{X}$, Weng $\mathrm{T}$, et al, A study of microemulsion systems for transdermal delivery of triptolide. J Control Release, 2004;98:427-36.

22. Gupta RR, Jain SK, Varshney M, Water-in-oil microemulsion as a penetration enhancer in transdermal drug delivery of 5fluorouracil. Colloids Surfaces B: Biointerfaces, 2005; 41:2532.

23. Elena P, Paola S, Maria RG, Transdermal permeation of apomorphine through hairless mouse skin from microemulsions. Int J Pharmaceutics, 2001; 226:47-51.

24. Rhee YS, Choi JG, Park ES, et al, Transdermal delivery of ketoprofen using microemulsions. Int J Pharmaceutics, 2001; 
228:161-70

25. Yuan Y, Li SM, Mo FK, et al, Investigation of microemulsion system for transdermal delivery of meloxicam. Int J Pharmaceutics, 2006; 321:117-23.

26. Li H, Pan WS, Li JY, Preparation, evaluation, and NMR characterization of vinpocetine microemulsion for transdermal delivery. Drug Dev Ind Pharm, 2004; 30: 657-66.

27. Kreilgaard M, Influence of microemulsion on cutaneous drug delivery. Advanced Drug Del Rev, 2002; 54:77-98.

28. Alana $\mathrm{R}$, Rades $\mathrm{T}$, Nicoll $\mathrm{J}$, et al, W/O microemulsions for ocular delivery: Evaluation of ocular irritation and precorneal retention.J Controlled Release. 2006; 111:145-52.

29. HaBe A, Keipert S, Development and characterization of microemulsions for ocular application. Eur J Pharmaceu Biopharma.1997; 43:179-183.
30. Vandamme TF, Microemulsions as ocular drug delivery systems: recent developments and future challenges. Progress in Retinal Eye Res. 2002; 21:15-34.

31. Newman MG, Takei H, Carranza FA, Clinical Periodontology, 9th edition, Philadelphia: WB Saunders, 2002.

32. Houshmand B, Rafiei A, Hajilooi M, et al, E-selectin and Lselectin polymorphisms in patients with periodontitis. J Periodont Res, 2009; 44:88-93.

33. Talegaonkar S, Azeem A, Ahmad FJ, et al, Microemulsions: A Novel Approach to Enhanced Drug Delivery. Recent Patents on Drug Delivery \& Formulation. 2008; 2:238-57.

34. Lily IL, Nandi I, Kim KH, Development of an ethyl laurate based microemulsion for rapid onset of intranasal delivery of diazepam. Int J Pharmaceu, 2002; 237:77-85. 